\title{
EFFECT OF PRESERVATIVES ON EXTENDING THE SHELF-LIFE OF RASOGOLLA
}

\author{
Dipa Das ${ }^{1}$, Md. Alauddin ${ }^{1}$, Md Atiar Rahman ${ }^{* 1}$, K. K. Nath ${ }^{2}$, Md. Rokonuzzaman ${ }^{3}$ \\ ${ }^{1}$ Department of Biochemistry and Molecular Biology, University of Chittagong, Chittagong-4331, Bangladesh \\ ${ }^{2}$ Bangladesh Council for Scientific and Industrial Research (BCSIR), Chittagong, Chittagong-4331, Bangladesh \\ ${ }^{3}$ Department of Statistics, University of Chittagong, Chittagong-4331, Bangladesh
}

Received 7 December 2009; received in revised form 20 May 2010

\begin{abstract}
The study aims, to find out an effective preservative to extend the shelf-life of Rasogolla, a highly popular sweetmeat due to its special appeal of taste, as well as to assess the effect of preservative on its biochemical and microbial status. Rasogolla available in local market has too short shelf life (2-3days) since its processing and preservation still lack standardization. In this research, Rasogolla was prepared in laboratory using calcium propionate, sodium metabisulfite, sorbic acid, sodium diacetate, sodium propionate, acetic acid, benzoic acid, sodium benzoate, butylated hydroxytoluene, butylated hydroxyanisole, P-4-hydroxybenzoate as preservatives followed by a comparative study of the biochemical and microbial status of both market and laboratory made Rasogolla. Use of sorbic acid and sodium metabisulfite showed the highest effectiveness in extending Rasogolla's shelf-life upto 24 and 15 days, respectively, whereas the combination of sorbic acid ( $0.1 \%)$ and sodium metabisulfite $(0.1 \%$ ) was found more effective when used separately rendering longer keeping quality up to 30 days ensuring color, flavor, taste and texture. Compositional analysis showed that total solid, moisture, fat, protein, carbohydrate and ash content of market Rasogolla were 75.87-83.17\%, 16.83-24.13\%, 2.86-4.31\%, 5.2-7.94\%, 64.26-73.30\% and 0.30-0.61\%, respectively, whereas those in laboratory made were $73.70-79.83 \%, 20.17-26.30 \%, 3.18-6.09 \% 6.9-8.59 \%, 61.18-65.25 \%$ and $0.30-0.61 \%$, respectively. Market Rasogolla were found more susceptible to microbial growth and contamination than those prepared in laboratory.
\end{abstract}

Keywords: Rasogolla, preservative, sorbic acid, channa, Na-metabisulfite

DOI:10.3329/cerb.v14i1.3940

\section{Introduction}

Cow's milk, as it is available in Bangladesh, has been used for preparing various types of dairy products and sweetmeats demanded in all ceremonies and festivals in Bangladesh [1]. Sweetmeats are made of Chhana which is an exclusive preparation of cow's milk. Rasogolla is one of the most popular, delicious, as well as nutritious among all sweetmeats in Bangladesh [2, 3]. It is also a Channa-based sweetmeat [4] composed of two components namely, small ball of freshly prepared Channa and sugar syrup where balls are put gently and heated to boiling. This is the traditional way of preparing Rasogolla (RG) throughout the country.

RG has been popular to all classes of Bangladeshi and Bengali people due to its high palatability and high food value. The social usage of RG bears so significance in each sphere of life that no social and religious function like Eid, puja, birthday, marriage ceremony, in our country is being worth without serving this sweetmeat [5]. It is necessarily supplied even in our random guest entertainment. The flavor and test of Rasogolla has, therefore, crossed our national boundary to meet the demand of Bengali and Bangladeshi people living abroad creating a potential source of earning foreign currency from RG exports. Already, a lot of dairy farms, milk processing industries have been developed both in Bangladesh and India [6] to meet the market demand of

*Corresponding author, Email:atiarh@yahoo.com fresh milk for preparing sweetmeats and other dairy products.

It is unfortunate that traditionally prepared $R G$ remains fresh only for 2-3 days for lack of hygienic manufacturing condition, knowhow for preservation and fair trade practice. $\mathrm{RG}$ is very much susceptible to microbial growth since milk is an excellent culture medium for many types of microorganisms, being high in moisture content and near neutral $\mathrm{pH}$. The presence of different types of microorganisms in milk products may cause souring, discoloration, acid formation, gassiness, proteolysis and many other effects. Microbial deterioration becomes evident due to the accumulation of metabolic products of psychrophilic bacteria [7]. Although the deterioration may be caused by food enzymes or by chemical reactions, the microbial contamination predominates over the others which can be removed by pasteurization, drying, freezing, irradiation, chemical preservatives those are in vogue as available means for preservation.

As the microorganisms are not completely killed by pasteurization, they may contaminate equipment and accumulate as a result of faulty cleaning. Chemical preservatives may therefore be used for the inhibition of growth and activity of microorganisms. But the use of preservatives is yet to take in place as, there is no patented and standardized procedure to produce high quality $\mathrm{RG}$, no regulatory control of hygienic manufacturing environment in the factory and no use of chemical preservative has been adopted so far in our country. Almost no research work has yet been conducted on 
the preservation of RG although a few works have been done on Rasomalai [5]. An attempt has been made in this study to find out an appropriate preservative to extend its shelf life ensuring its quality and export potential as well as to prevent its spoilage in local market. This study also aims to encourage the sweetmeat producers in manufacturing and selling of quality RG which may substantially advance the prospect for sweetmeat entrepreneurship.

\section{Experimental}

The experiment was conducted at the Fruits and Vegetable Research Division of Bangladesh Council for Scientific and Industrial Research (BCSIR) laboratories, Chittagong, during the period from March - September, 2007. RG collected from 10 different sweetmeat shops of local market and those prepared in the laboratory under strict hygienic condition (hygienic code IS10974, part 3: 1984) were taken as sample for analysis and comparative study.

\subsection{Preparation of $R G$}

$1 \mathrm{~kg}$ of fresh cow's milk was heated to its boiling temperature in a stainless steel pan and kept for 10 minutes. $4 \%$ acetic acid was added to the pan for complete coagulation of Chhana. After filtering through a piece of muslin cloth, water was expelled out of the coagulated milk leaving Channa onto the cloth. $240 \mathrm{~g}$ of Chhana was obtained from $1 \mathrm{Kg}$ of milk.

The quantity of Channa obtained $(240 \mathrm{~g})$ was ground, broken into bits and kneaded with flour $(0.2 \mathrm{~g})$ in such a way that no sign of crack was observed when Chhana balls were made from the processed Chaana dough. Sugar (225g) was dissolved in $675 \mathrm{ml}$ of water and the solution was boiled for 1 hour to make clean syrup. Small Chhana balls were then put gently in the boiling sugar syrup and cooked for 2530 minutes to swell the Chhana balls. When the colors of the balls became slightly dark, the cooking was over. The Channa-balls soaked in syrup became large in size due to osmosis activity and weight increased more than two times. It takes 30-35 minutes for cooling and serving Rasogolla. Hygienic environment was strictly maintained in this procedure. Calcium propionate $(\mathrm{CaP})$, sodium metabisulfite $(\mathrm{NaM})$, sorbic acid $(\mathrm{SA})$, sodium diacetate $(\mathrm{NaD})$, sodium propionate $(\mathrm{NaP})$, acetic acid (AA), benzoic acid (BA), sodium benzoate $(\mathrm{NaB})$, butylated hydroxytoluene (BHT), butylated hydroxyanisole (BHA), P-4-hydroxybenzoate (PHB) were added as preservatives to observe the sample.

\subsection{Proximate biochemical composition}

To assess the biochemical and chemical composition of the prepared $\mathrm{RG}$, their protein content $(\mathrm{g} / \mathrm{kg})$ (Kjeldahl method, standard methods, 1960), fat content $(\mathrm{g} / \mathrm{kg})$ (Soxh'let extraction), carbohydrate content $(\mathrm{g} / \mathrm{kg})$, and moisture content $(\mathrm{g} / \mathrm{kg})$, ash content $(\mathrm{g} / \mathrm{kg})$, total solid content $(\mathrm{g} / \mathrm{kg})$, were determined.

\subsection{Microbial analysis of $R G$}

For microbiological analysis, RG was kept with preservatives for periodical observation and analysis of bacterial growth, fungal growth and total viable count (TVC). For both quantitative and qualitative analysis, samples were diluted serially using sterile distilled water. Appropriate dilutions required $1 \mathrm{ml}$ each to be plated in duplicate (pour plate method). Nutrient agar, MacConkey broth and Malt extract agar were used for this investigation while the Nutrient agar plate and MacConkey's broth tube were incubated at 370C for $24 \mathrm{hrs}$ and the Malt extract agar plates for $48 \mathrm{hrs}$.

\subsection{Sugar analysis}

For a periodic determination of sugar, a few (3-5) RG samples, kept with selective preservatives, were subjected to sugar analysis by Volumetric Copper reduction method [8]. The volume of sugar solution required to reduce completely $10 \mathrm{ml}$ mixed Fehling's solution was determined using methylene blue $(1 \%)$ as the redox indicator for assessing the end point. In this research, total sugar amount and the amount of reducing sugar were estimated.

\subsection{Statistical analysis}

Statistical analysis was conducted through two-way ANOVA using the software SPSS 11.5.

\section{Results and Discussion}

A total of ten different groups of RG (free of preservative) collected from local market of Chittagong City and RG prepared in the laboratory (added with different preservatives) were used to assess the relative contents of total protein, fat, carbohydrate, moisture, ash, solid, of all the samples in each category. Shelf-life and vulnerability to microbial contamination as well were checked for all the samples and a comparison was figured out between the market RG and laboratory made RG on the basis of above mentioned parameters.

All foods undergo varying degree of deterioration during storage. Food is subjected to physical, chemical and biological deterioration [9]. Deterioration may include losses in organoleptic desirability, microbial attack, nutritional value, safety and aesthetic appeal. Food may change in color, texture or flavor. Permitted amount of preservatives [10] which is known as GRAS (Generally Recognized As Safe, per section 201(32) of the U.S. Federal Food, Drug and Cosmetic Act as amended in 1958) [11] were used to RG prepared in laboratory to avoid such deterioration.

\subsection{Observation of shelf-life of $R G$}

A large quantity of RG were made in BCSIR laboratory, Chittagong and kept on preservation using various preservatives by dividing into few groups. Each group contained 3 sweet balls in $100 \mathrm{ml}$ of sugar syrup. The observation pointed out that the shelf-life of market RGs without preservatives on an average lasted for 2-3 days whereas laboratory made RGs with preservatives remained fresh for much 
Table 1: Shelf-life of RG without and single preservative

\begin{tabular}{|c|c|c|c|c|}
\hline Group & $\begin{array}{l}\text { No of } \\
\text { samples }\end{array}$ & $\begin{array}{l}\text { Preservatives } \\
\text { in sugar syrup }\end{array}$ & Quantity (\%) & $\begin{array}{r}\text { Average shelf } \\
\text { life (days) }\end{array}$ \\
\hline $\mathrm{A}$ & $\mathrm{N}=5$ & None & & $2-3$ \\
\hline B & $\mathrm{N}=5$ & $\mathrm{CaP}$ & $0.2-0.3$ & 5 \\
\hline $\mathrm{C}$ & $\mathrm{N}=5$ & $\mathrm{NaM}$ & $0.1-0.2$ & $10-15$ \\
\hline D & $\mathrm{N}=5$ & SA & $0.05-0.1$ & $20-24$ \\
\hline E & $\mathrm{N}=5$ & $\mathrm{NaD}$ & $0.2-0.3$ & $3-5$ \\
\hline $\mathrm{F}$ & $\mathrm{N}=5$ & $\mathrm{NaP}$ & $0.2-0.25$ & $3-3$ \\
\hline G & $\mathrm{N}=5$ & BA & 0.1 & 3 \\
\hline $\mathrm{H}$ & $\mathrm{N}=5$ & $\mathrm{NaB}$ & 0.1 & 3 \\
\hline I & $\mathrm{N}=5$ & PHB & $0.1-0.2$ & $7-10$ \\
\hline J & $\mathrm{N}=5$ & BHA & 0.1 & 4 \\
\hline K & $\mathrm{N}=5$ & BHT & 0.1 & 4 \\
\hline
\end{tabular}

Table 2: Shelf-life of RG with different combinations of preservative

\begin{tabular}{cllrr}
\hline Group & $\begin{array}{l}\text { No of } \\
\text { samples }\end{array}$ & $\begin{array}{l}\text { Preservatives } \\
\text { in sugar syrup }\end{array}$ & Quantity (\%) & $\begin{array}{r}\text { Average shelf } \\
\text { life (days) }\end{array}$ \\
\hline A & $\mathrm{N}=5$ & CaP +AA & $(0.2+0.1)-(0.3+0.1)$ & $10-13$ \\
B & $\mathrm{N}=5$ & NaM + SA & $(0.1+0.1)$ & 30 \\
C & $\mathrm{N}=5$ & NaD+AA & $(0.4+0.1)$ & 5 \\
D & $\mathrm{N}=5$ & NaP+AA & $(0.2+0.1)$ & 3 \\
\hline
\end{tabular}

longer duration than those of market RGs (Table 1 and Table 2).

From Table 1 and 2, it was observed that combined effect of preservatives is more predominant on RG's keeping quality than that of a single preservative. Addition of SA $(0.1 \%)$ and $\mathrm{NaM}(0.1 \%)$ when used alone extend the shelf life upto 24 and 15 days, respectively, showing their highest activity among the single preservatives. BA $(0.1 \%), \mathrm{NaB}(0.1 \%)$, and $\mathrm{NaP}(0.2 \%-0.25 \%)$ have no or little effect on the keeping quality of RG. These preservatives can keep RG fresh for 3 days, on an average, which is about the same keeping period of RGs without any preservative whereas $\mathrm{CaP}$ is more effective in extending the shelf life of RG, to around 5 days. Propionic acid and propionates are used normally against molds $[12,13]$ although the mechanism of action is not clearly established but it is evidenced that they prevent microbes from producing energy they need.

Combination of preservatives were used as well to improve the shelf life of RG and the shelf-lives obtained for different combinations were compared with those obtained for single preservative. Combination of $\mathrm{NaM}$ and SA $(0.1 \&$ $0.1 \%$ ) was found to extend shelf life up to 30 days which was more than those observed for $\mathrm{NaP}, \mathrm{NaD}, \mathrm{CaP}$ each combined with AA providing the shelf-life 10, 5 and 3 days, respectively. The greater effect of NaM and SA is due to the effectiveness of NaM against bacteria, the most harmful causative agent for sweetmeat spoilage, whereas SA and its salts are actually known to inhibit yeast and mold growth, but are less effective against bacteria. Therefore, the addition of $\mathrm{NaM}$ and SA kills or prevents growth of microbes responsible for spoiling sweetmeats, especially RG.

Derivatives of AA i.e. $\mathrm{NaD}$ have been recommended [14] as preservative. However in this research, it was observed that addition of $\mathrm{NaD}(0.2 \%)$ could not improve the shelf-life of RG which implies that this preservative has no effect on sweetmeats. But the addition of $0.4 \% \mathrm{NaD}$ with $0.1 \%$ AA can keep the RG fresh for 5 days (Table 2). AA was found more effective against yeast and bacteria than against molds, and its effectiveness increased with a decrease in $\mathrm{pH}$, which would favor the presence of the undissociated acid. Sodium salt of benzoic acid such as $\mathrm{NaB}$ has been extensively used as an antimicrobial agent in food items. But in this study it was observed from Table 1 that the addition of BA $(0.1 \%)$ and also $\mathrm{NaB}(0.1 \%)$ could not improve the shelf-life. This signifies that both of these preservatives have no effect on the shelf-life of RG.

Antioxidants have been used as preservatives in different foods. In this work, two antioxidants have been selected as preservatives. Table 1 shows that the addition of $0.1 \%$ BHA and $0.1 \%$ BHT has no effect on the shelf-life. It keeps the sweetmeats fresh for only 4 days. Table 1 also showed that the addition of $0.1 \%$ PHB improves the shelf-life of RG for 5 days whereas the increased amount of PHB (0.2\%) improves the shelf-life up to 7 days.

\subsection{Biochemical composition of $R G$}

As RG is a Chhana based food product, it plays a significant role in health due to its fairly high protein and fat content, minerals, vitamins etc. Therefore, for maintaining the quality of RG, the principal constituents especially protein, fat, carbohydrate, total solid and ash play an important role.

In the present study it was revealed that the proximate biochemical composition of market RG was about 75.87$83.17 \%$ total solid, $16.83-24.13 \%$ moisture, $2.86-4.31 \%$ fat, $5.2-7.94 \%$ protein, $64.26-73.30 \%$ carbohydrate, and 0.30 $0.61 \%$ ash. The proximate percentage of laboratory made RG was $73.70-79.83 \%$ total solid, $20.17-26.30 \%$ moisture, $3.18-6.09 \%$ fat, $6.9-8.59 \%$ protein, $61.18-65.25 \%$ carbohydrate and $0.3-0.61 \%$ ash.

The total solid contents of market RG were higher than that of laboratory indicating inferiority of the sources [15]. Higher moisture content was noticed in laboratory made RG than market RG. The higher amount of moisture indicates good quality RG and sometimes it may give good flavor. Gupta et al. [16] said overall textural quality was significantly correlated with moisture. Hardness of RG is also influenced by moisture content [17].

Laboratory made RG contains higher protein level as compared to that collected from market. As per the Bangladesh Standard Testing Institute (BSTI) [18] specification of minimum protein content of RG should be $5 \%$. Higher protein percent increases the quality of RG. Fat content is slightly lower in market RG than laboratory made RG. Increased level of fat content in laboratory RG is due to effect of pure Chhana. Higher carbohydrate content in market indicates that most of the adulterated materials added with the ingredients are rich in carbohydrate and decreased sponginess.

Study reveals the fact that laboratory made RG without preservative remains fresh for not more than 3 days. It is a great problem for the manufacturers of RG and if sold keeping more than 3 days becomes health hazard for the consumers. Sweetmeats makers, therefore, should be insisted to use preservatives to improve the shelf-life as well as textural quality of RG, so that they can sell this product everywhere in the country and can also export to other countries.

From the organoleptic examination it is clear that only the addition of the combination of SA and NaM keeps RG un- 
changed up to 30 days and this combination could be one of the best preservatives which can highly improve the shelflife of RG. However, the sweetmeat manufacturers can also use either SA or Na-M individually to improve shelf-life of RG. All these preservatives increase the shelf-life of RG by inhibiting the microbial growth as well as maintaining the nutritional composition properly. Samples studied without any preservative, underwent change in color, flavor and taste in 3 days. These parameters undergo total spoilage on keeping beyond 3 days.

\subsection{Total and reducing sugar analysis}

Sugars, especially all monosaccharides, which possess free aldehyde or ketone groups, are known as reducing sugars whereas the non-reducing sugars are the linked product of monosaccharides through aldehyde or ketone group. Reducing sugar particularly can react with other food constituents, such as, amino acids of proteins, to form compounds that affect the color, flavor and other properties of food.

In this research, sugar analysis has been done periodically on $3,7,15,24$, and 30 days. It was observed that the amount of sucrose (Table 3) was decreased day by day due to enzymatic degradation. With the increasing days, the spoilage occurs in RG resulting in the microbial growth on the RG. These microorganisms degrade the sucrose into glucose and fructose. In the samples where any preservative is not used, the amount of sucrose decrease rapidly (Table 3). But the amount remains same in the sample where the combination of SA and NaM was used. On the other hand, the amount of reducing sugar (Table 4) increased day by day as the samples undergoes spoilage. In this study higher amount of reducing sugar was found in the samples kept without preservative. Also the other samples showed a gradual increase in the amount of reducing sugar with the increasing days.

Table 3: Comparative sucrose content analysis of the samples with and without preservative

\begin{tabular}{rrrrrrr}
\hline Storage & \multicolumn{5}{c}{ Total sugar as sucrose (\%) } \\
\cline { 2 - 7 } (Days) & Control & SA & CaP +AA & PHB & NaM & SA + NaM \\
\hline 3 & 34.57 & 32.53 & 37.72 & 33.18 & 31.88 & 32.41 \\
7 & 27.6 & 32.47 & 33.89 & 33.08 & 31.85 & 32.38 \\
15 & 26.3 & 32.4 & 31.28 & 32.86 & 31.78 & 32.33 \\
24 & 25 & 32.31 & 27.51 & 32.79 & 31.66 & 32.29 \\
30 & 20.73 & 20.23 & 23.68 & 32.62 & 31.5 & 32.25 \\
\hline
\end{tabular}

Table 4: Comparative reducing sugar analysis of the samples with and without preservative

\begin{tabular}{rrrrrrr}
\hline $\begin{array}{c}\text { Storage } \\
\text { (Days) }\end{array}$ & Control & SA & CaP +AA & PHB & NaM & SA + NaM \\
\hline 3 & 0 & 0 & 0 & 0 & 0 & 0 \\
7 & 1.27 & 0 & 0.55 & 0 & 0.59 & 0 \\
15 & 3.16 & 0 & 2.8 & 0 & 1.6 & 0 \\
24 & 3.42 & 0 & 3.09 & 1.58 & 1.96 & 0 \\
30 & 3.59 & 0.6 & 3.21 & 1.71 & 2.33 & 0.25 \\
\hline
\end{tabular}

\subsection{Microbial assay of $R G$}

The primary objective in adding a preservative is to prevent the surface growth of molds and to extend shelf-life. To determine the microbiological quality of the sweetmeat total viable count (TVC), yeast and mold count and Coliform test were done for the RG preserved with different preservatives. No Coliform bacterium (Table 5) was found in Coliform test performed with sweetmeat preserved for different period (3, 7, 15, 24 and 30 days) of time. Result obtained from bacterial count (TVC) and yeast and mold count showed that some preservatives were more active against bacteria than fungi and some were more active against fungi than bacteria.

Table 5: Bacterial growth on RG with single preservative

\begin{tabular}{rrrrrr}
\hline Storage & \multicolumn{5}{c}{ No. of bacterial colonies/g for different preservatives } \\
\cline { 2 - 6 } (Days) & Control & SA & CaP & NaM & PHB \\
\hline 3 & 3225 & 294 & 523 & nil & 2700 \\
7 & 6900 & 2100 & 3329 & nil & 6900 \\
15 & 90176 & 33665 & 37640 & nil & 90176 \\
24 & 89704 & 43225 & 39800 & nil & 89704 \\
30 & 51608 & 65700 & 42750 & 17 & 51608 \\
\hline
\end{tabular}

Among the preservatives used, NaM was found very effective in preventing bacterial growth (Table 5). It was found to prevent bacterial growth up to 30 days. Few bacterial colonies were found in RG preserved with NaM after 30 days. On the other hand, SA was found very effective against fungi. Only 4 mold colonies per gram of sample were found after 30 days of preservation (Table 6). Due to effective-

Table 6: Fungal growth on RG with single preservative

\begin{tabular}{rrrrrr}
\hline $\begin{array}{r}\text { Storage } \\
\text { (Days) }\end{array}$ & \multicolumn{4}{c}{ No. of Yeast and mold colonies/g for different preservatives } \\
\cline { 2 - 6 } Control & \multicolumn{1}{c}{ SA } & CaP & NaM & PHB \\
\hline 3 & 19 & Nil & 2 & Nil & 12 \\
7 & 82 & Nil & 17 & 2 & 64 \\
15 & 188 & 1 & 48 & 19 & 160 \\
24 & 162 & 3 & 85 & 41 & 183 \\
30 & 299 & 4 & 129 & 85 & 232 \\
\hline
\end{tabular}

ness of sorbic acid against fungi and $\mathrm{NaM}$ against bacteria, a combination of $\mathrm{SA}$ and $\mathrm{NaM}$ was used to preserve RG. This combined preservative showed excellent activity (Figure 1 , highly significant at $p<0.0000005$ ) against both bacteria and fungi. It was found to prevent microbial growth effectively up to 30 days (Table 7). Other preservatives $(\mathrm{CaP}$, PHB) used were found less effective in preventing bacterial and fungal growth. The quality of the RG preserved with these preservatives was deteriorated with the growth of bacteria and fungi. Undesirable or unpleasant taste and off flavor were developed with some bacterial changes (Table 8).

Table 7: Bacterial and fungal growth on RG with the combination of SA and $\mathrm{NaM}$

\begin{tabular}{rrr}
\multicolumn{1}{l}{ and NaM } & & \\
\hline Storage (Days) & Bacteria & Fungus \\
\hline 3 & Nil & Nil \\
7 & Nil & Nil \\
15 & Nil & Nil \\
24 & Nil & Nil \\
30 & 3 & 2 \\
\hline
\end{tabular}

RG, available in local market, manufactured with no preservative sustain only for a shorter duration (3 days) causing a great loss both to national economy and human health. Sweetmeat manufacturers, therefore, are to be encouraged to use preservatives to improve the shelf-life and textural quality of RG helping the people to avoid spoiled RG and to ensure its export potential. 

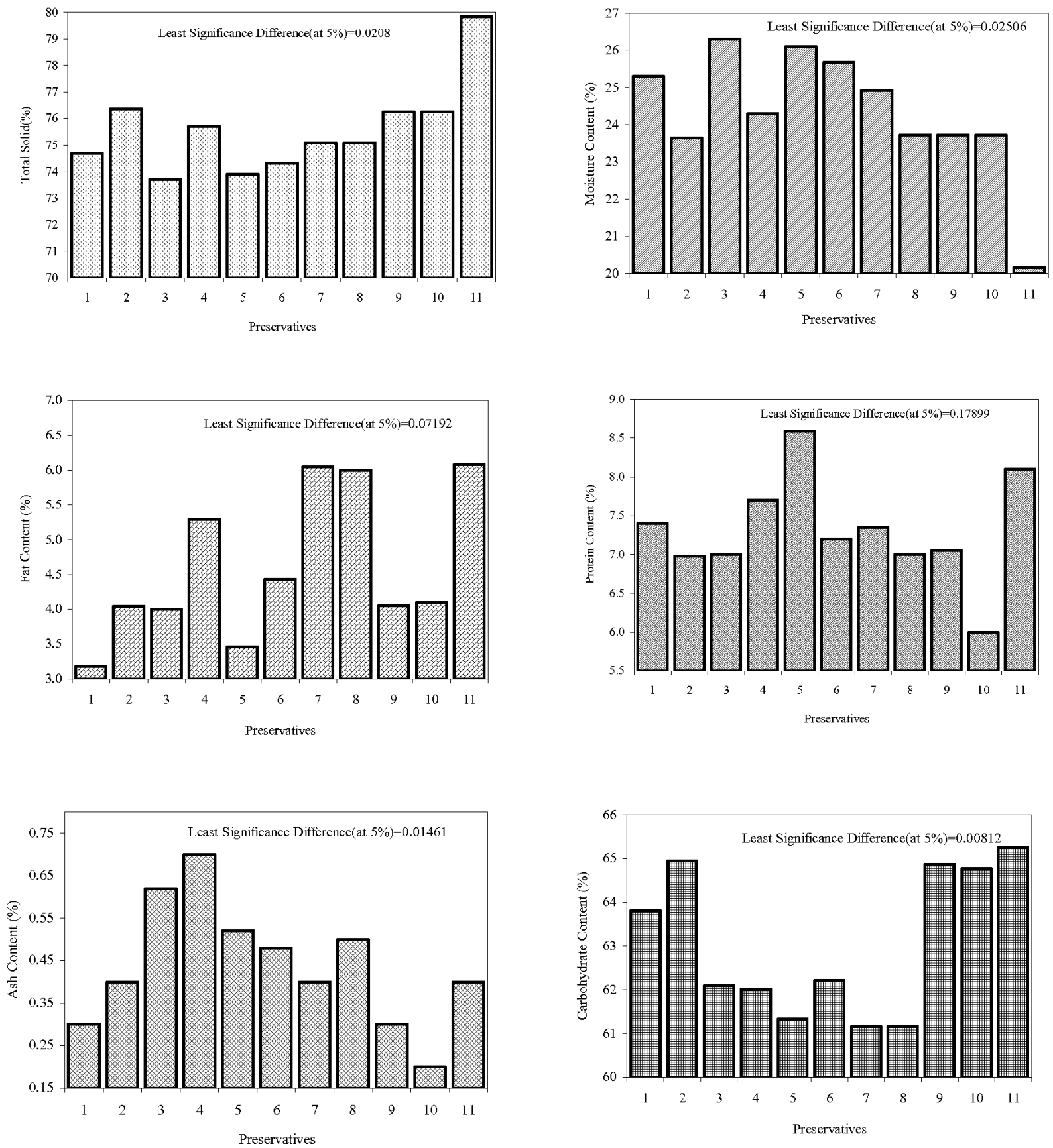

Figure 1: Biochemical composition of RG with the addition of preservative, where 1. No preservative; 2 . Calcium propionate (CaP); 3 . Na-metabisulfite $(\mathrm{NaM})$; 4. Sorbic acid $(\mathrm{SA})$; 5. Sodium diacetate $(\mathrm{NaD})$; 6. Sodium propionate $(\mathrm{NaP})$; 7. Benzoic acid $(\mathrm{BA})$; 8. Sodium benzoate $(\mathrm{NaB})$; 9 . p-4-hydroxy benzoate (PHB); 10. Butylated hydroxyanisole (BHA); 11. Butylated hydroxytoluene (BHT) 
Table 8: Observation on the organoleptic changes of RG in different day's intervals

\begin{tabular}{rrrrrrr}
\hline $\begin{array}{r}\text { Storage } \\
\text { (Days) }\end{array}$ & Control & SA & Ca-P & Na-M & P4HB & SA+Na-M \\
\cline { 2 - 7 } & SC & ++ & ++ & ++ & ++ & ++ \\
7 & FG \& CCFT & ++ & ++ & ++ & SCC & ++ \\
15 & - & ++ & FG & ++ & FG & ++ \\
24 & - & ++ & CCFT & - & - & ++ \\
30 & - & - & - & - & - & ++ \\
\hline SC =Slight changes, FG=Fungal Growth, +=Good, - = Spoiled \\
CCFT=Change of color, Flavor and Taste, SCC= Slight change of color
\end{tabular}

$\mathrm{CCFT}=\mathrm{Change}$ of color, Flavor and Taste, $\mathrm{SCC}=$ Slight change of color

\section{Conclusion}

It can be definitely concluded that addition of SA along with $\mathrm{NaM}$ is one of the best preservatives which can highly improve the shelf-life of RG ensuring the optimum biochemical composition and preventing the microbial growth on $\mathrm{RG}$. Textural quality is also maintained very properly in using these preservatives.

\section{References}

[1] Chourasia S, Bengalee's on personal property, Ananda Bazar Patrika: 4 November, 1983

[2] Rao MS, Rao MR, Ranganadham M and Rao BVR, Studies on preparation of chhana from Buffalo milk and its suitability for Rasogolla manufacture, Indian Journal of Dairy Science, 1989. 42:pp. 810-816

[3] Mannan A, Hossain M and Islam M, Standard and Standardization of Sweetmeats. Standard of Traditional Made Chhana and Rasogolla, BAU Research Progress, 1994. 8:pp. 410-413

[4] Bhattacharya DC and Raj D, Studies on the production of Rasogolla Part-1 Traditional method, Indian Journal of Dairy Science, 1980. 33:pp. 237-243

[5] Islam M, Rahman S, Alam M and Mannan A, Manufacture of Rossomalai and It's Quality Attribute: An Indigenous Milk Sweetmeat of Bangladesh, Pakistan Journal of Nutrition, 2003. 2(5):pp. 300-304

[6] Kulia R, Sen D and Misra R, Milk Sweets of Eastern India, Dairy development in Eastern India, 2000. 13:pp. 64-73

[7] Morita R, Psychrophilic bacteria., Bacteriological Reviews, 1975. 39(2):p. 144

[8] Lane J and Eynon L, Determination of reducing sugars by means of Fehling's solution with methylene blue as internal indicator, Journal of the Society of Chemical Industry, 1923. 42:pp. 32T-37T

[9] Potter N and Hotchkiss J, Food Science, CBS Publications, 5th edition, 1997

[10] Banwart GJ, Basic Food Microbiology, AVI Publishing Company, Westport, Connecticut, 1st edition, 1979

[11] Jay JM, Modern Food Microbiology, Chapman \& Hall, New York, 4th edition, 1995

[12] Ingle J, Some preliminary observations on the effectiveness of propionates as mold inhibitors on Dairy products, Journal of Dairy Science, 1940. 23:p. 509

[13] Heseltine W, A note on sodium propionate., The Journal of pharmacy and pharmacology, 1952. 4(2):pp. 120-122

[14] Davidson PM, Sofos JN and Branen AL, Antimicrobials in food, CRC Press, Boca Raton, 3rd edition, 2005

[15] Adhikari A, Mathur O and Patil G, Micro-and macro-structure of cow, buffalo and mixed milk rasogolla: a comparative scanning electron and light microscope study, Le Lait, 1992. 72(5):pp. 475-489

[16] Gupta S, Patel A, Patil G, Desai H and Ghosh B, Texture studies on selected Indian dairy products: composition-texture relationships, Internation Dairy Federation Special Issue, 1993. 2:pp. 176-182

[17] Ravichandra M, Mishra H and Das H, Optimization of process parameters for the production of Rasogolla from cow milk, Journal of Food Science and Technology, 1997. 34(1):pp. 46-49

[18] BSTI, BS specification for rasogolla, 1993 